\title{
Patient Safety at the Frontlines: The Provincial Context
}

$\mathrm{I}$ n early 2014, Healthcare Quarterly hosted a second roundtable discussion on the subject of patient safety, this time with some of the leading provincial healthcare organizations across Canada. The participants were:

$\mathbf{R B}=\mathrm{G}$. Ross Baker (moderator), Professor, Institute of Health Policy, Management and Evaluation, University of Toronto

BB = Bonnie Brossart, CEO, Health Quality Council of Saskatchewan

DC = Daniel Chartrand, Chairman, Patient Safety Committee, Canadian Anesthesiologists' Society; President (or Chairman), Groupe Vigilance pour la sécurité des soins, MSSS (Québec)

TF = Theresa Fillatre, Senior Policy Advisor, Canadian Patient Safety Institute - Chair, Atlantic Health Quality and Patient Safety Collaborative

AT = Annemarie Taylor, Provincial Director, BC Patient Safety \& Learning System

JT = Joshua Tepper, CEO, Health Quality Ontario

DW = Dale Wright, Senior Project Lead, Health Quality

Council of Alberta

The following text is not a verbatim transcript of the meeting. Rather, it distils the main content while, we hope, preserving the energy, enthusiasm and insights each person brought to the discussion.
RB: Ten years after the founding of the Canadian Patient Safety Institute (CPSI) and the Adverse Events Study, progress seems to have been slow. Why is that, and what have we learned?

TF: While there are many more players in the patient safety arena these days, people we support still see a lot of tolerance for unexplained practice variations. One of the other challenges is the provincial structuring of our health system and relationships with the federal government.

We also underestimated the complexity of patient safety improvement work. Safety is the core dimension of quality, yet we've isolated it. And we still have to work on privacy legislation solutions to overcome perceived and real obstacles to sharing lessons learned.

DC: When the law was changed in Quebec, we had to train a lot of people - risk managers, patient safety officers and healthcare workers. But we've realized that when you go back to train a team again, half its original members have retired or moved on to other jobs.

However, there are some signs of positive change. For example, many students and residents are now talking about and studying patient safety. The University of Montreal also has a new program that takes a patient-partner approach, whereby patients are becoming experts in teaching patient safety to healthcare workers. As well, the Federation of Specialized Physicians has made patient safety a priority for all its associations. 
BB: Regrettably, there's still a belief that mistakes are inevitable. Also, there have been lots of good intentions over the last 10 years, but that's not the same as "intentionality." To paraphrase Saskatchewan's past deputy minister, I would say it has been, to some degree, a leadership failure.

DW: But maybe we've been more successful than we want to give ourselves credit for. There actually is a greater awareness about safety now than there was 10 years ago. But I think that's also come with higher expectations, by ourselves and patients.

There's also been progress in analyzing adverse events to focus on identifying contributing system factors and making system improvements. Think about some of the work we've done around disclosure and the great work of Safer Healthcare Now!

AT: Perhaps measuring progress depends on perspective. Trying to use traditional measurement to reflect progress may not be the way to go.

As well, healthcare has evolved quite rapidly, especially with regard to patient care practices. An example in BC is the implementation of NSQIP, which began only three years ago but we now have a stable system that's informing thinking about surgical care.

Compared to five years ago, in $\mathrm{BC}$ we see far greater attention paid at the level of governance to adverse events that harm patients. We are also doing better with individual adverse event management and problem-solving.

There has also been a definite change in how leaders at many levels perceive patient safety and adverse events: they are paying more attention, support greater transparency, are more collaborative in their improvement efforts and are more focused on the patient. I have also seen changes in the perception of what is acceptable risk because patients are more engaged, better informed and have higher expectations.

RB: Ten years ago, most of us did not think that we would be sitting here in 2014 pointing to isolated examples of success and not to some sort of broad-scale achievements. That raises the question, what do you think are the critical things that must be done - by your organization or collaboratively - to overcome complacency and address complexity?

BB: We have to build capability in our workforce - from the leadership all the way through to point of care. Success requires intentionality around leaders' commitment to zero tolerance for harm, and then acting in a way that demonstrates that commitment and removes the barriers.

In Saskatchewan, that's been the real game-changer for us. We talked a good talk in this province for several years. We participated in a number of the great initiatives, but then the work went quiet. What's changing now is there's again a zero acceptance for harm to patients. It doesn't mean we're there yet, but there's a commitment to strategic oversight right through to where the work is being done.

TF: You can put your shoulder to the wheel, engage folks, do the measurements and support the work, but as soon as we let up measurement and using the data, momentum for sustainability ceases. That tells me there are too many priorities on the table.

\section{Atlantic Health Quality and Patient Safety Collaborative (AHOPSC)}

The Atlantic Health Quality and Patient Safety

Collaborative (AHOPSC) was launched by the Atlantic Deputy Ministers of Health in May 2011, from the origins of the Atlantic Node Safer Healthcare Now! Steering Committee. Membership includes the Chairs of the provincial quality and patient safety committees in the four Atlantic provinces, health ministry persons responsible for quality and patient safety, the New Brunswick (NB) Health Council and representatives of health regions (system). The Canadian Patient Safety Institute (CPSI) serves as coordinating secretariat. The primary mandate is to make recommendations to the deputy ministers on common quality/patient safety policy or capacity-building strategies. Priorities in action at this time include: development of critical mass of local board members to provide quality and patient safety governance education on an ongoing basis, with the intent that these resources be shared between provinces, and that the Health Association of Nova Scotia take on the coordination of the program through a contractual arrangement with CPSI and the provinces; delivery of a hybrid patient safety officer education program locally augmented by online learning and coaching through Canadian Healthcare Association and CPSI partnership; and planning for the third Atlantic Learning Exchange (ALE) in May 2015 in Halifax. An inter-provincial planning committee is leading that work, using the feedback from the 250 participants in the highly successful ALE 2013, Moncton, NB. The primary goal is spotlighting Atlantic quality and patient safety initiatives that are making a sustainable system impact and to share contacts and lessons learned. The AHOPSC was recognized by the Health Council of Canada as an emerging innovation on its portal. The greatest success of the AHQPSC is the working relationships that have developed between the provinces and the enthusiasm to embrace collaborative change strategies together.

\section{For more information, see www.saferhealthcarenow.ca/ EN/shnNewsletter/Pages/}


We also haven't fully harnessed governments in their leadership role. In the Atlantic region, we've seen restructuring in every province. Each time that happens, the players change, the strategic leadership is lost and any momentum or constancy of purpose is eroded, and we dedicated our resources to catch up.

But I believe there's a growing appetite for moving patient safety forward. For example, the CPSI hosted a consortium meeting at the end of January 2014. The aim was to establish some kind of framework for action that would help to align what the provinces are doing, whereby all could see themselves in a framework, come to terms with what some of the initial system-level measures are and sort out the leadership roles with the key organizations in order to reduce duplication and accelerate progress.

DW: Theresa's comment about ongoing restructuring taking its toll in terms of a loss of momentum, loss of strategic leadership and changing focus underscores the fact that it's been a wild ride here in Alberta.

To address the fact patient safety has sort of fallen off the radar, we need to recognize that safety is an important part of some of these other priorities, and keep reminding government and senior leaders that it is a way to achieve goals such as accessibility and accountability.

DC: Here in Quebec, we sometimes still have to take a stepby-step approach using pilot projects. If you can show that not only is a solution better for patients and patient safety but at the same time hospitals are saving money, then you get everybody on board to go ahead.
JT: For Health Quality Ontario, patient safety is wellentrenched, but just one component of the broader quality agenda. Moving forward, the issue will be about spread - about trying to create changes and replicate successes.

AT: In BC, we've realized there are two sides to the coin: making care better and safer and making care less expensive and more efficient really are interdependent. As long we see those dimensions as separate, they're going to be competing for attention and resources.

TF: In the Atlantic provinces, when we're choosing patient safety initiatives we're also taking into account areas in which we will see impact on other dimensions, including financial.

BB: When I think about the conversations that we're now having in Saskatchewan, safety definitely has a prominence, but it's not exclusive. Our conversations at the leadership tables now speak about how we look at quality, cost of care, access, what safety looks like and morale.

The real challenge going forward is the line of sight from the micro-system, where the work is being done, to the macrosystem, where policy and levers are developed to facilitate change.

JT: At Health Quality Ontario, we are trying to drive alignment among the different parts of the organization, including our IT side. This is particularly important in the acute-care sector, where there is a lot of activity, resources and players. We want to complement that and provide supportive resources, data reporting, etc.

\section{"Groupe Vigilance" for Healthcare Safety (Quebec)}

More than 12 years ago, after the tragic death of her daughter from a medication error, Michelle BeaucheminPerreault has mobilized all her energy to prevent such events. She was able to convince the politicians to modify the Quebec Health Law to improve patient safety and to establish a culture of safety. She also became the first patient representative in the "Groupe Vigilance."

As an interprofessional group of patient safety experts, Groupe Vigilance has received the mandate to make recommendations to the Ministry of Health on its own initiative or at the request of the Ministry. For example, looking at more than 450,000 adverse events reported last year in the Quebec Registry http://publications.msss.gouv.qc.ca/ acrobat/f/documentation/2013/13-735-02W.pdf (cf. pp. 12-13), the Quebec Minister of Health has recently asked the Groupe Vigilance to make recommendations to prevent and to minimize the consequences of the two most frequent problems reported: falls and medication-related adverse events. For this specific mandate, two sub-groups of experts have been created and they will soon make their final recommendations.

The Groupe Vigilance is also: reviewing the results of the accreditation process in the Quebec healthcare organizations, identifying best healthcare practices and collaborating in the improvement of healthcare practices, proposing strategies to promote and improve the culture of safety, participating in educational activities about patient safety (French version of ASPIRE, symposium, interprofessional continuous professional development), etc.

Finally, if one mother has been initially able to change the Quebec healthcare system, today the Groupe Vigilance can still count on the contribution of expert patient-partners who are actively training other patients and healthcare professionals. Working with and for the patients, the Groupe Vigilance hopes to help improve the quality of care and patient safety. 
We're going to be looking at things like transitions of care and working with the HealthLinks quite a bit. Even though safety won't be a solo issue, it will have a steady presence in all aspects of our work.

RB: Ten years ago we thought it would be critical to develop a system that ensured there would be reporting of many, if not all, patient safety events and that there would be analysis of many, if not all, of those events individually or in groups. Were our expectations met in those systems?

DC: At the hospital level, that's probably been the case. It's mandatory in Quebec to report all adverse events; whatever is added to the hospital database is sent to the Quebec National Database. We get about 450,000 events a year and we are starting to make sense out of those data. Not surprisingly, we found that falls and medication errors are the two top problems. The health minister then authorized the creation of "ad-hoc" expert groups to examine those issues. We are hoping that within the next few years, we will also be able to learn more at the micro-system level.

AT: In BC, we've had a provincial electronic reporting system in place since 2011. It's used by everyone that works in healthcare in all settings. So, well over 100,000 people can potentially report in our system.

Aside from data and analysis, some sort of reporting and learning system is an important part of the overall policy framework. We're also seeing more and more that where the data are most meaningfully applied is at the local level. And we are now trying to take those examples and share them across the province, so that we can start to bring about the spread of best practices at the larger system level. Taking a provincial collaborative approach to reporting has also led to standardization in language and processes for responding to and investigating events.

Our focus now is on looking at ways we can build a more comprehensive picture of patient safety. To that end, we're applying some work that's been done by Charles Vincent and the Health Foundation in the United Kingdom on measurements and monitoring of safety.

BB: In Saskatchewan, we are making some headway with how we report issues related to safety. I think the next frontier is replication or spread.

What's changing now is the behaviour of leaders. Every couple of weeks we bring all the CEOs together in a room or on the line to have a conversation. These meetings always start with a critical incident that has happened in an organization, and we use that as a springboard for learning.

JT: I actually worry about the amount of reporting that's occurring, in part because I don't know how well the data are being used. There are frameworks and structures in place, but the opportunity now is to determine how they are operationalized.

DW: Over the past five or six years, the Alberta Health Services (AHS) has been working on standardizing procedures related to reporting and event analysis. As well, AHS has a reporting-and-

\section{The Health Quality Council of Alberta: Patient Safety Activities}

The Health Quality Council of Alberta (HOCA) is an

independent organization with a mandate to promote and improve patient safety and health service quality in Alberta. Our activities are guided by the Alberta Quality Matrix for Health, which recognizes safety as a distinct dimension of quality. The HOCA is primarily an influencer organization with four main pillars of activity: measurement, quality and safety reviews, quality and safety initiatives and education. Our measurement team routinely surveys Albertans on their experience and satisfaction with health service quality and safety. This year we will be releasing a report on patient perspectives of continuity of care. We will also release the results of resident experience surveys in supportive living and long-term care, and undertake a pilot survey with home care clients. The reviews team is currently examining quality and safety practices in the inpatient parenteral nutrition process within Alberta Health Services, as well as quality and safety management across the spectrum of continuing care services. In 2014 we will publish an online abbreviations toolkit to provide healthcare providers in different care environments, strategies to curtail the use of abbreviations in medication communication. We are currently developing a framework document to guide practices around a just approach to administrative reviews of individuals involved in patient harm events. Our patient safety education program continues to improve knowledge and practices related to patient safety at both the undergraduate and practice levels. Two successful certificate courses are being offered through Continuing Medical Education at the University of Calgary: the Patient Safety and Quality Management certificate course and the Investigating and Managing Patient Safety Events certificate course.

\section{For more information please visit www.hqca.ca}


learning system that's used internally. Unfortunately, though, we don't know how effective it is, as information is not shared outside AHS

RB: My next question addresses how we create systems that are able to identify issues and then translate insights on the frontline into strategic activities (and vice versa). What do you see in terms of good examples of linking frontline staff and leadership in creating effective quality improvement and patient safety efforts?

TF: Our two-year Atlantic Spread and Sustainability Learning series revealed that with our regional structures, the notion of linking executive sponsors to middle managers and frontline managers to frontline clinical teams didn't work. Executive sponsors' spans of control were huge in the large regions and they couldn't fulfil these roles, which they had to delegate down the line - sometimes successfully and sometimes not. Leadership changed and structures changed. We also learned it was difficult to maintain physician input to the local frontline team processes.

There's just too much on the plate, especially when regional structures are changing at the same time that these kinds of change initiatives are going on or governments are reorganizing their health departments and reallocating regional resources. In those instances, patient safety and other initiatives stall and have to restart - with different people each time.

DC: In Quebec, it's roughly the same. Even if patient representatives are sitting on hospital boards to ensure that what the patients and frontline caregivers see as problems are discussed at the highest level, some CEOs are not yet taking patient safety seriously in terms of priorities.

JT: Part of the challenge is how we think about leadership. In Ontario, the really good HealthLinks are full of great leaders. One of the powers of HealthLinks is to bring to the forefront a new group of leaders that were not well-recognized in historical structures and processes; for example, in primary and home care.

BB: During the last two years in Saskatchewan, our commitment to consistent methodologies and principles has started to change the way leaders think and behave. Unlike in the past, today you see leaders not just visiting but having conversations with staff and patients about what care is really like.

What's also fundamentally different is the capability we're building in our leaders through rigorous, unrelenting learning. These people are expected to commit to 80 days above and beyond their regular work over a two-year period to learn new methods and actually apply them.

DW: One thing I've learned is that changes work best when you have a leader who truly has a passion for and a commitment to an initiative. For a change initiative to be successful, a leader has to bring an existing passion and commitment to the project. Change is unlikely to occur when a leader without true commitment is delegated to be the project sponsor.

AT: I believe it's essential for leaders to keep a relentless focus on quality and safety, despite the fact that change and challenges are always arising at the leadership level. There must also be a connection between senior leaders' goals and what's important

\section{Health Quality Ontario's Patient Safety Improvement Efforts and Initiatives}

Patient safety and improved patient care are key priorities for Health Quality Ontario (HQO), but just one aspect of a broader quality agenda. Each branch of HQO works collaboratively and with providers and partner organizations to facilitate improved patient safety and support organizations as they work to improve the care they deliver every day.

HQO's patient safety public reporting focuses on providing the public with comprehensive updates on patient safety in hospitals. The public can access this hospitalspecific information and compare Ontario's hospitals and the overall provincial rate.

HOO also supports improved patient safety in Ontario's health system through comprehensive quality improvement initiatives. HQO equips frontline workers with the tools necessary to improve outcomes, patient experiences and patient safety by providing them with access to a suite of resources, best practices, change ideas and on-the-ground expert coaching support.

For patient safety to improve, the health system must be confident that the treatments it administers and the technology it uses are safe and current. HQO's Evidence Development and Standards branch conducts evidencebased analyses to evaluate the safety, efficacy, effectiveness and cost-effectiveness of health interventions. The findings of these analyses inform HQO's quality improvement activities and its public reporting strategy.

In the years to come, HOO will continue to spread change by evaluating health interventions and technologies, supporting frontline providers as they work to improve patient safety and the care that they deliver, and report to the public on the performance of their health system.

To learn more about HOO, please visit www.hqontario.ca 
to the frontline, and ways for the groups to give feedback to each other.

TF: Creating stronger links between leaders and the frontline makes sense to me, as does bringing patients into the picture as partners in care design.

JT: I don't know whether greater involvement of patients is going to help create more energy and more communication between the senior levels and frontline leaders. Overall, though, I think it will create a better shaping of the agenda at each level.

RB: Some believe that sharing lessons across the country would be valuable, yet it doesn't happen in an organized or systematic fashion. What do you think the mechanisms are for us to learn from each other?

AT: There are some pan-Canadian initiatives that are already working to achieve those kinds of goals. One example is CPSI's virtual forum, a good example of a multi-dimensional approach to sharing learning and lessons.

Our experience in $\mathrm{BC}$ with safety and quality has shown us there are two levels of learning we can achieve: by individuals and by larger groups. Sharing and learning in groups can help us to establish best practices, and I wonder whether there's a way to be quite deliberate and focused about this by bringing people together across the country around particular issues rather than having a global data-collection approach.

DC: In Quebec, the language barrier is often a problem. Because of that, I don't know how we can easily share podcasts and videos, and have a networking system. As well, I'm not sure how we can encourage people from Quebec to participate in a Canadian initiative when, even at the provincial level, things are still somewhat fragmented.

TF: I think some of the issues to solve pertain to provincial privacy legislation, which is an impediment (real or perceived) to sharing and not reinventing the wheel. Taking a national policy look at enabling privacy legislation might help.

Another way to facilitate knowledge sharing will be through the national summits CPSI is organizing with clinicians, policymakers and so on across the country, beginning in March 2014. Those summits will be on key topics of focus that have been established as common system priorities through third-party evaluation and feedback: infection prevention and control, surgical care safety, homecare safety and medication safety with attention on the patient care transitions in each area of focus.

BB: Sharing and learning across the country seems timely, and I believe it always has merit. As I listened to today's conversation, all I could think of is we know it's complicated at the organizational level, but it's even more complex at the level of regions, provincial health systems and across the country.

The best place to start might be to focus on a common pebble; for example, medication errors or surgical site infections. That would be useful regardless of whether we're using Lean methodology in Saskatchewan while others might be using QI methodology.

JT: I believe there are more similarities than disparities across the country. In fact, I think it's easier to share learning about patient safety than it is, say, primary care models or EHR (where there's lots more variation).

\section{Health Quality Council, Saskatchewan}

Within Saskatchewan, there are several important activities underway that are improving safety for both patients and

for those who work in the health system. Saskatchewan continues to be actively involved in a number of Canadian Patient Safety Institute (CPSI) programs, including the Surgical Safety program (via the implementation of the surgical site infection bundle); the Medication Safety program (via the Medication Reconciliation program); and infection prevention and control. The Saskatchewan Health Quality Council (HOC) has endorsed Canadian Patient Safety Week (CPSW) 2014 and we will promote to our audiences the campaign's safe care messages during CPSW in October.

As part of the province's implementation of Lean principles and methodology, it is required that all leaders pursuing Lean Leader certification are taught and participate in a Mistake Proofing project. These four-month quality improvement projects focus on eliminating defects in clinical processes that may result in harm to those who use the healthcare system and to those who are working in it. HQC coordinates the selection and scheduling of these projects as part of the Provincial Kaizen Promotion Office function we took on last April. During the past two years, 85 Mistake Proofing projects have been undertaken; more than half have reached zero defects, with the remainder at less than one per cent defects at four months. Saskatoon Health Region is currently prototyping a Safety Alert/Stop the Line System inspired by Virginia Mason Medical Center. Our goal is that by 2017 we will have one system for the entire province.

\section{For more information, see} www.hqc.sk.cal 
RB: Given the resources and challenges of 2014, what do you think we need to do next in order to make patient safety a more fundamental part of daily clinical work and daily system work?

TF: It's really about the will to work together. No one organization or province can do it all on their own. We at least need to get the national organizations working together to better understand what the needs and the readiness in the provinces are.

I think it's about focusing on and finishing a few things. I don't see us doing that very well today - and that's also from my experience as a surveyor with Accreditation Canada as well.

DC: I agree that partnerships should increase between regions and provinces. In Quebec, we are trying to find a new model that would empower clinical units to create quality teams on every possible point of care, in partnership with patients. One other thing I'm pushing is the education and engagement of healthcare professionals, especially new ones.

JT: I believe the critical strategic lever will be a focussed learning platform. It can't feel like an add-on to a fairly full plate, and it's got to have a clear value add.
BB: For me, the critical lever is engaging in activities that are fundamentally going to grow and nourish a culture of safety, both for patients as well as those who provide care. It's also all about leaders' verbal and visible commitment to safety.

DW: In Alberta, we have learned that it is increasingly difficult to separate safety and quality issues. We therefore need to be more intentional about talking about safety in everything we do.

AT: As Theresa mentioned, let's stay the course and keep focused. And, as Daniel said, training new healthcare providers and leaders is going to be a huge lever. I would add, too, that it will be critical to meet patients' growing expectations for safety and quality care, as well as communicating with them and ensuring they and their families are front and centre. We'll also have to deal with the challenges posed by an ageing workforce and ageing patients.

\section{BC Patient Safety and Quality Council}

The British Columbia (BC) Patient Safety and Quality Council supports activities that improve care quality, including initiatives under the BC Ministry of Health's Clinical Care Management program. The Council facilitates and promotes improvement projects across the province and at each of the health authorities, in hand hygiene, critical care, care for seniors, heart failure, venous thromboembolism, medication reconciliation and antipsychotic use in residential care. Highlights include creating the BC Sepsis Network; leading a provincial collaborative on care for stroke and transient ischemic attack patients in emergency departments; and supporting initiatives designed to improve surgical care quality, including the National Surgical Quality Improvement Program, the surgical checklist and infection prevention. Building capability and capacity for improvement is also an important focus, and is achieved through the Quality Academy, the Board and Executive Learning Series, the annual Quality Forum and monthly online learning activities.
The BC Patient Safety \& Learning System (BCPSLS) remains an important component of the patient safety policy framework. The first province-wide system of its kind in Canada, BCPSLS is used by all health authorities across acute, residential, community and ambulance care settings to identify, manage and learn from adverse events, near misses and hazards. Increased emphasis on data analytics is aimed at better measurement and monitoring of patient safety. The BCPSLS blog is proving to be an effective means of engaging people and sharing stories of improvement and change. Patient's View, a version of BCPSLS that captures patient and family perspectives on safety, is showing early signs of success and exciting potential.

\section{BC Patient Safety \& Quality Council: www.bcpsqc.ca}

BC Patient Safety \& Learning System: www.bcpsls.ca 